\title{
Red Onion (Allium cepa L.) Methanolic Extract Increases Extracellular Nucleotide Hydrolysis in Rat Serum
}

\author{
Janayne Luihan Silva1, Bruno Quintanilha Faria², Vinícius Marques Arruda², \\ Fernanda Cardoso da Silva ${ }^{3}$, Joyce Ferreira da Costa Guerra ${ }^{2,3}$, Cristina Ribas Fürstenau ${ }^{3,4^{*}}$ \\ ${ }^{1}$ Instituto de Ciências Biológicas, Universidade Federal de Minas Gerais, Belo Horizonte, Brazil \\ ${ }^{2}$ Curso de Biotecnologia, Universidade Federal de Uberlândia, Patos de Minas, Brazil \\ ${ }^{3}$ Programa de Pós-graduação em Biotecnologia, Instituto de Biotecnologia, Universidade Federal de Uberlândia, Patos de Minas, \\ Brazil \\ ${ }^{4}$ Centro de Ciências Naturais e Humanas, Universidade Federal do ABC, Santo André, Brazil \\ Email: *c.furstenau@ufabc.edu.br
}

How to cite this paper: Silva, J.L., Faria, B.Q., Arruda, V.M., da Silva, F.C., da Costa Guerra, J.F. and Fürstenau, C.R. (2020) Red Onion (Allium cepa L.) Methanolic Extract Increases Extracellular Nucleotide Hydrolysis in Rat Serum. Open Journal of Applied Sciences, 10, 864-876.

https://doi.org/10.4236/ojapps.2020.1012061

Received: November 27, 2020

Accepted: December 27, 2020

Published: December 30, 2020

Copyright $\odot 2020$ by author(s) and Scientific Research Publishing Inc. This work is licensed under the Creative Commons Attribution International License (CC BY 4.0).

http://creativecommons.org/licenses/by/4.0/

\section{(c) (i) Open Access}

\begin{abstract}
Ectonucleotidases are enzymes involved in nucleotides metabolism. The amount of circulating nucleotides may modulate distinct pathophysiological processes in the vasculature, including platelet aggregation and vascular tone. Onion (Allium cepa L.) phenolic compounds modulate enzymatic activity. The present study evaluated the total phenolic content of red onion methanolic extract, its antioxidant capacity, and its ability to interfere in nucleotides hydrolyses in rat serum. Total phenolic content was determined with the Folin-Ciocalteau reagent using gallic acid as a standard, while total flavonoid content was obtained through the aluminum chloride colorimetric method with quercetin as a standard. Antioxidant capacity was evaluated from the ability of the extract to scavenge ABTS ++ and DPPH • radicals. ATP, ADP, AMP, and p-Nph-5'-TMP hydrolyses were colorimetrically determined in response to different onion extract concentrations $(0,125,250,500$, or 1000 $\mu \mathrm{g} / \mathrm{mL}$ ). Phenolic content of the extract was $54.35 \mathrm{mg} \mathrm{GAE} 100 \mathrm{~g}^{-1}$ sample, while flavonoid content was $7.22 \mathrm{mg}$ quercetin $\mathrm{g}^{-1}$ sample. The IC50 value for ABTS•+ was $374.13 \pm 7.52 \mu \mathrm{g} / \mathrm{mL}$, while it was $440.29 \pm 15.17 \mu \mathrm{g} / \mathrm{mL}$ for DPPH•. Red onion extract increased ADP and p-Nph-5'-TMP hydrolysis. The results confirmed that red onion contains high content of antioxidant, mainly flavonoids, and high antioxidant capacity. Additionally, biochemical studies suggest that the increased ADP breakdown may be important to regulate vascular processes. As it occurs for other enzymes, the antioxidant capacity of onion extract may neutralize reactive oxygen species (ROS) formation and favor ectonucleotidase activity and the hydrolysis of ADP, a major
\end{abstract}


platelet agonist.

\section{Keywords}

Red Onion, Flavonoids, Reactive Oxygen Species, Ectonucleotidases, Vascular Homeostasis

\section{Introduction}

Extracellular nucleotides and nucleosides of purines (ATP, ADP, and adenosine) and pyrimidines (UTP and UDP) regulate distinct biological processes in various tissues [1], including the cardiovascular system, where they can promote platelet aggregation and modify vascular tone [2], among other effects. After reaching the extracellular medium, these molecules initiate signaling cascades by binding to their specific membrane receptors, the purinoceptors, generally named P1 and P2 [3].

Purinergic signaling is inactivated through nucleotide metabolization, performed by a multienzymatic complex composed of ectonucleotidases. These enzymes are located on the cell surface and may also be found in the interstitial medium or within body fluids; they exhibit broad substrate specificity and tissue distribution [4]. Nucleotide hydrolysis includes a role for ecto-nucleoside triphosphate diphosphohydrolases (E-NTPDases), ecto-nucleotide pyrophosphatase/phosphodiesterases (E-NPPs), ecto-5'-nucleotidases, and alkaline phosphatases [5]. Depending on the considered family, ectonucleotidases typically hydrolyze nucleoside tri-, di-, and monophosphates and di-nucleoside polyphosphates to produce nucleoside diphosphates, nucleoside monophosphates, nucleosides and inorganic phosphate $(\mathrm{Pi})$ or pyrophosphate $(\mathrm{PPi})[6]$. It is important to highlight that other compounds from purine metabolism, such as inosine, hypoxanthine, and uric acid, possess important antioxidant activity and contribute to redox balance and the control of different pathologies [7] [8]. Extracellular nucleotide concentration is then controlled by their enzymatic hydrolysis.

Reactive oxygen species (ROS) are atoms, molecules, or ions derived from oxygen metabolism. Most ROS are highly reactive and can interact with DNA, lipids, and proteins to cause tissue damage and risk of cardio-metabolic diseases if they are not neutralized by antioxidant compounds [9]. These molecules inhibit extracellular purine catabolism in endothelial cells and thus modify cardiovascular disease pathophysiology [10]. In chronic hypertensive individuals, these effects favor platelet aggregation [11].

Onion (Allium cepa L.) may help in the control of several pathologies due to its high concentration of phenolic compounds that may exert protective actions against cardiovascular diseases [12]. Of the onions, the red variety exhibits the highest content of these compounds, which may confer to this vegetable greater 
antioxidant activity and greater activity in ROS elimination [13]. Previous studies demonstrated that phenolic compounds exert a number of important biological activities in the cardiovascular system, such as antioxidation, platelet aggregation and adhesion inhibition, vasodilation, and lipid metabolism modulation [14]. Phenolic compounds are generally found in natural products and are well studied because of their antioxidant properties against oxidative damage [14].

The control of cardiovascular functions is also related to purinergic signaling, and understanding the mechanisms involved in this context is extremely important for the search for new drugs and therapies to treat cardiovascular diseases. It is known that the phenolic compounds present in onion may act as enzymatic activity modulators. However, their properties regarding the modulation of ectonucleotidase activities, and how they would be related to the activity of these enzymes in the cardiovascular system, have not yet been reported. Thus, the objective of the present study was to investigate whether red onion extract could modulate ectonucleotidase activities in rat serum.

\section{Materials and Methods}

\subsection{Chemicals}

Substrates ATP, ADP, AMP, p-nitrophenyl thymidine 5'-monophosphate (p-Nph-5'-TMP), 2,2-diphenyl-1-picrylhydrazyl radical $(\mathrm{DPPH} \bullet$ ),

6-hidroxi-2,5,7,8-tetramethylchrome-2-carboxilic acid (Trolox), quercetin, 2,20-azinobis-3-ethylbenzothiazoline-6-sulfonic acid (ABTS $\bullet$ ), and Folin-Ciocalteau reagent were procured from Sigma-Aldrich (St. Louis, MO, USA). Other chemicals used in this study were of the highest purity.

\subsection{Obtaining Red Onion Extract}

Red onions were purchased from a local supermarket in Patos de Minas, Minas Gerais, Brazil, from conventional plantations and were handled as previously described [15], with minor modifications. Briefly, approximately $500 \mathrm{~g}$ red onions were minced and dried in a drying oven (402-5D, Ethik Technology, SP, Brazil) at $60^{\circ} \mathrm{C}$ for $48 \mathrm{~h}$. Dried contents were then triturated, and approximately $10 \mathrm{~g}$ of the powder was weighed and kept under magnetic stirring (MA-085/5L, Marconi, SP, Brazil) with $50 \mathrm{~mL}$ methanol for $2 \mathrm{~h}$. Extracts were filtered through filter paper (C42, Unifil, SP, Brazil), dried in a rotatory evaporator (Model 802, Fisatom, SP, Brazil), and stored at $-80^{\circ} \mathrm{C}$ (Ultra freezer CLS20-86V, Coldlab, SP, Brazil) until use.

\subsection{Measurement of Total Phenolic and Flavonoid Content}

Total phenolic content in red onion extract was spectrophotometrically analyzed (Spectrophotometer UV-340G, Gehaka, PR, Brazil) at $760 \mathrm{~nm}$ using the Folin-Ciocalteau reagent, as previously described [16]. Gallic acid was used as the standard for quantification and expression of the results. Phenolic content is ex- 
pressed as mg gallic acid equivalents (GAE) $100 \mathrm{~g}^{-1}$ sample. Total flavonoid content was determined by using the aluminum chloride colorimetric method previously described [17]. Quercetin was used as a standard for the calibration curve. Data are expressed as mg quercetin equivalents $(\mathrm{QE}) \mathrm{g}^{-1}$ red onium extract.

\subsection{Antioxidant Capacity}

\subsubsection{2,2'-Azino-Di-(3-Ethylbenzthiazoline Sulfonic Acid) (ABTS)•+ Radical Scavenging Activity}

The antioxidant capacity of red onion extract was determined using ABTS•+ diammonium salt radical cation decolorization assay, according to the method previously described [18]. Briefly, ABTS was dissolved in deionized water to a 7 $\mathrm{mM}$ concentration. ABTS radical cation (ABTS $\bullet+$ ) was produced by reacting the ABTS solution with $2.45 \mathrm{mM}$ potassium persulfate and allowing the mixture to stand in the dark at room temperature for $12-16 \mathrm{~h}$ before use. This solution was diluted in deionized water to an absorbance of $0.700 \pm 0.02$ at $734 \mathrm{~nm}$. The ABTS•+ diluted solution $(1 \mathrm{~mL})$ and $50 \mu \mathrm{L}$ water (blank), Trolox standard or sample, were mixed and the absorbance was read at $734 \mathrm{~nm}$ for 6 min using a spectrophotometer. The percentage of ABTS $\bullet+$ inhibition was calculated using the formula scavenging activity $(\%)=[(A 0-A$ test $) /(A 0)] \times 100$, where $A 0$ was absorbance of the ABTSO•+ solution without antioxidant compounds and Atest was the absorbance of the ABTS and tested sample combination after 6 min. Analyses were performed in triplicate.

\subsubsection{2,2-Diphenyl-1-Picrylhydrazyl (DPPH)• Radical Scavenging Activity}

To confirm its antioxidant property, the ability of red onion extract in scavenging $\mathrm{DPPH} \bullet$ radicals was also determined. Antioxidant capacity using DPPH• was determined according to the method previously described [19]. The absorbance at $515 \mathrm{~nm}$ was measured after $30 \mathrm{~min}$. The decline in the initial DPPH. solution $(60 \mu \mathrm{M})$ absorbance indicated the radical scavenging activity of the sample. Trolox was used as a standard. The radical scavenging activity percentage was calculated as $[(A 0-A$ test $) /(A 0)] \times 100$, where $A 0$ is the initial DPPH absorbance without antioxidant compounds and Atest is the absorbance after the $30 \mathrm{~min}$ reaction. Analyses were performed in triplicate.

\subsection{Animals}

To test whether the red onion extract could modulate circulating ectonucleotidase activity, rat serum was collected. Male Wistar rats (approximately $250 \mathrm{~g}$ ), 60 to 90 days old, were kept at $25^{\circ} \mathrm{C}$ in cages of up to 5 animals and subjected to a 12 hours light/ dark cycle. They received water and rat chow ad libitum. All protocols were in accordance with the guidelines of the Ethics Committee on the Use of Animals (Project Number 067/15 CEUA-UFU) from the Universidade Federal de Uberlândia, and all efforts were made to minimize the number of 
animals used in this study and their suffering. Blood was drawn after decapitation and allowed to clot at room temperature for $30 \mathrm{~min}$. Blood was centrifuged in glass tubes at $5000 \mathrm{x} \mathrm{g}$ for $5 \mathrm{~min}$ at room temperature. The resultant serum samples were kept on ice and immediately used for enzymatic assays.

\subsection{Extracellular ATP, ADP and AMP Hydrolysis}

Assays for E-NTPDase and ecto-5'-nucleotidase in serum samples were performed using a modification of the previously described method [20]. The reaction mixture contained $112.5 \mathrm{mM}$ Tris $-\mathrm{HCl}, \mathrm{pH} 8.0$, water, $1.0 \mathrm{mg}$ protein, and different red onion extract concentrations $(0,125,250,500$ or $1000 \mu \mathrm{g} / \mathrm{mL})$. Extract was added during preincubation that was performed for $10 \mathrm{~min}$ in a $37^{\circ} \mathrm{C}$ water bath (CT-245-28, Cientec, MG, Brazil), prior to substrate addition. To start the reactions, $3.0 \mathrm{mM}$ of substrates (ATP, ADP or AMP) were added in a final reaction volume of $200 \mu \mathrm{L}$. After 40 -min incubation, $200 \mu \mathrm{L}$ trichloroacetic acid (TCA; 5\%, final concentration) was used to stop the enzymatic reactions. Incubation times and protein concentrations were chosen to ensure the linearity of the enzymatic reactions. The amount of inorganic phosphate (Pi) released was examined by a colorimetric method as previously reported [21] using a spectrophotometer set at $630 \mathrm{~nm}$ (Spectrophotometer UV-340G, Gehaka, PR, Brazil). Controls to correct for non-enzymatic substrate hydrolysis were performed by adding serum after the reactions were stopped with TCA. All samples were performed in duplicate. Enzyme activities were generally expressed as nmol Pi released per min per mg protein.

\section{7. p-Nph-5'-TMP Hydrolysis}

E-NPP activity in serum samples were evaluated according to a previously described method [22]. The reaction mixture that contained $100 \mathrm{mM}$ Tris- $\mathrm{HCl}$ (pH 8.9) was preincubated for $10 \mathrm{~min}$ in a $37^{\circ} \mathrm{C}$ water bath (CT-245-28, Cientec, MG, Brazil) with approximately $1.0 \mathrm{mg}$ serum protein, water, and different red onion extract concentrations $(0,125,250,500$, or $1000 \mu \mathrm{g} / \mathrm{mL})$. Enzyme reactions were started by the addition of p-Nph-5'-TMP (5'TMP, an artificial marker substrate for E-NPP activity) to a final concentration of $0.5 \mathrm{mM}$. After $8 \mathrm{~min}$, $200 \mu \mathrm{L} 0.2 \mathrm{~N} \mathrm{NaOH}$ was added to the reaction to stop it. Incubation times and protein concentrations were chosen to ensure the linearity of the reaction. The amount of p-nitrophenol released from the substrate was measured at $400 \mathrm{~nm}$, using a molar extinction coefficient of $18.8 \times 10^{-3} / \mathrm{M} / \mathrm{cm}$. Controls to correct for nonenzymatic substrate hydrolysis were performed by adding serum after the reaction was stopped with $\mathrm{NaOH}$. All samples were performed in duplicate. Enzyme activities were generally expressed as nmol p-nitrophenol released per min per mg protein.

\subsection{Statistical Analysis}

Data are expressed as the mean \pm standard deviation (SD). Statistical analysis 
was performed using GraphPad Prism 5.0 (GraphPad Software Inc., San Diego, CA). Data were analyzed by one-way analysis of variance (ANOVA). Significant differences between groups were determined with the Newman-Keuls post hoc test. The Student's $t$ test was performed to compare IC50 values for free radical scavenging activity data. Differences were considered significant at $\mathrm{p}<0.05$.

\section{Results and Discussion}

Dark-colored vegetables usually have a high phenolic compound content, a feature that confers sensory characteristics to these plants and can play broad biological functions in the body, such as protection against macromolecule oxidative damage induced by ROS [23] [24] [25]. Red onion extract was chosen in the present study due to its recognized high total phenolic content [13], and because it is a widely consumed vegetable worldwide.

Total phenolic content of the crude red onion extract was $54.35 \mathrm{mg}$ GAE 100 g-1 sample (Table 1) and was comparable to previous data [13] [23] [26]. Different types of phenolic compounds such as anthocyanins, quercetin, ferulic acid, gallic acid, protocatechuic acid, and kaempferol have been previous reported in red onion extract [27]. Flavonoids are the most predominant components of onion, being this vegetable one of the major sources of all flavonoids consumed in the human diet [24] [25]. In the present study we also found a high level of flavonoids (7.22 mg quercetin $\mathrm{g}^{-1}$ ) (Table 1 ). It is thus noteworthy that we could extract a considerable amount of phenolics, mainly as flavonoids, from red onion.

Oxidative damage is now considered to be a major event in myriad diseases, including cardiovascular disorders. Thus, marked scientific investigations focus on the possible role of natural antioxidants in delaying or suppressing oxidative stress and secondary effects like enzyme activities modulation [26]. There is a great need for antioxidants, dietary or supplementary, to increase endogenous antioxidant activity, and a wide variety of phenolic compounds and flavonoids present in vegetables are now being experimentally investigated [26]. As mentioned before, compounds generated in the purine degradation also present antioxidant effects [7] [8].

Table 1. Total phenolic and flavonoid content and radical scavenging activity of the red onion extract. Different superscript letters indicate significant differences by Student's t test. Results are expressed as mean $\pm \mathrm{SD}, \mathrm{n}=3$.

\begin{tabular}{cc}
\hline Measure & Concentration \\
\hline Phenolic content $\left(\mathrm{mg} \mathrm{GAE} 100 \mathrm{~g}^{-1}\right)$ & $54.35 \pm 0.32$ \\
Flavonoid content $\left(\mathrm{mg} \mathrm{QE} \mathrm{g}{ }^{-1}\right)$ & $7.22 \pm 0.06$ \\
IC50 for ABTS $\bullet(\mu \mathrm{g} / \mathrm{mL})$ & $374.13 \pm 7.52^{\mathrm{b}}$ \\
IC50 for DPPH $\bullet(\mu \mathrm{g} / \mathrm{mL})$ & $440.29 \pm 15.17^{\mathrm{a}}$ \\
\hline
\end{tabular}


In this study, we determined the free radical scavenging capacities of the red onion extract using DPPH• and ABTS•+ assays. The IC50 value for ABTS•+ was $374.13 \pm 7.52 \mu \mathrm{g} / \mathrm{mL}$, while it was $440.29 \pm 15.17 \mu \mathrm{g} / \mathrm{mL}$ for DPPH•(Table 1 ). Antioxidant capacity detected by ABTS assay was significantly higher to that by DPPH assay, in agreement with previous studies [28] [29]. Analyses of DPPH• and $\mathrm{ABTS} \bullet+$ radical inhibition are frequently used to determine antioxidant activity. Both are stable radicals that produce color in the reaction, and when reduced by the donation of hydrogens present in the sample, the decay in absorbance can be measured spectrophotometrically. The red onion extract obtained in this study presented important antioxidant activity. There was a dose-dependent increase in radical scavenging activity and the onion extract inhibited $60 \%$ of the ABTS $\bullet+$ and $58 \%$ of the DPPH• at the highest concentration $(500 \mu \mathrm{g} / \mathrm{mL})$ tested (Figure 1). Vegetables have different antioxidant mechanisms, and due to the wide variety of potential antioxidant compounds, such as vitamins, flavonoids, phenolic acids, and sulfur compounds present in plants, differences in the method of extraction (e.g., the solvent used) may result in notable variability in the extract antioxidant activity [25]. Previous studies showed a strong positive correlation between ABTS and DPPH assays with total phenolics content, suggesting that phenolic compounds are the major contributors to antioxidant properties of foods and plant extracts [28]. Red onion extract was then used in the present study to perform functional tests upon serum ectonucleotidase activities.

E-NTPDase and ecto-5'-nucleotidase are found anchored to the cell membrane and or in a soluble form that circulates in the blood. The activity of both families is affected by the oxidative state of the medium [11] [30] [31]. Each ectoenzyme exhibits specific nucleotide preferences [31], and this factor may be the reason for the different responses of ATP, ADP and AMP hydrolysis to red onion extract.

E-NTPDase hydrolyzes ATP and ADP, and there are some molecules that inhibit its activity [31]. However, only a few reported molecules can increase its activity. Red onion extract did not alter ATP hydrolysis in blood serum (Figure 2). On the other hand, it induced $70 \% \mathrm{ADP}$ hydrolysis at $250 \mu \mathrm{g} / \mathrm{mL}$ (Figure 3). ADP is an important agent in platelet aggregation [32]; thus, its increased hydrolysis may suggest that the extract would be able to remove ADP from circulation and potentially inhibit platelet aggregation.

Ecto-5'-nucleotidase efficiently hydrolyzes AMP to adenosine [33], which is an important vasodilator molecule in the vasculature. The coordinated action of these enzymes is important for the efficient regulation of extracellular nucleotides and adenosine levels. However, similar to ATP hydrolysis, AMP hydrolysis was not modified by red onion extract at any evaluated concentration (Figure 4).

E-NPPs exhibit a broad substrate range that includes nucleoside tri- and diphosphates, dinucleoside polyphosphates, ADP-ribose, NAD+ and artificial substrates like p-Nph-5'-TMP, but not AMP [6]. The use of artificial substrates is 
important for the differentiation between E-NPPs and E-NTPDases due to the similarity between the location and the substrates that the two families hydrolyze. The role of E-NPPs is highly variable, and this enzyme family is probably the most important one involved in extracellular dinucleoside polyphosphate hydrolysis, which generates PPi and other important molecules in signal transmission [6] [34]. NPP1, for example, participates in bone mineralization and vascular smooth muscle cell calcification [35] [36] when it hydrolyzes extracellular ATP to AMP, which generates extracellular PPi that can function as a calcification inhibitor. NPP2 (autotaxin) is a secreted enzyme present in several biological fluids, including serum and seminal plasma [30], where it performs its catalytic activity. E-NPP activity is inhibited by ethylenediaminetetraacetic acid (EDTA) [6]; however, there is no specific activator described for this enzyme. Red onion extract significantly increased p-Nph-5'-TMP (the artificial substrate marker for E-NPP activity) hydrolysis by approximately $40 \%$ when applied at 500 and $1000 \mu \mathrm{g} / \mathrm{mL}$ (Figure 5), data that suggest the extract could act physiologically on the previously mentioned effects in serum.

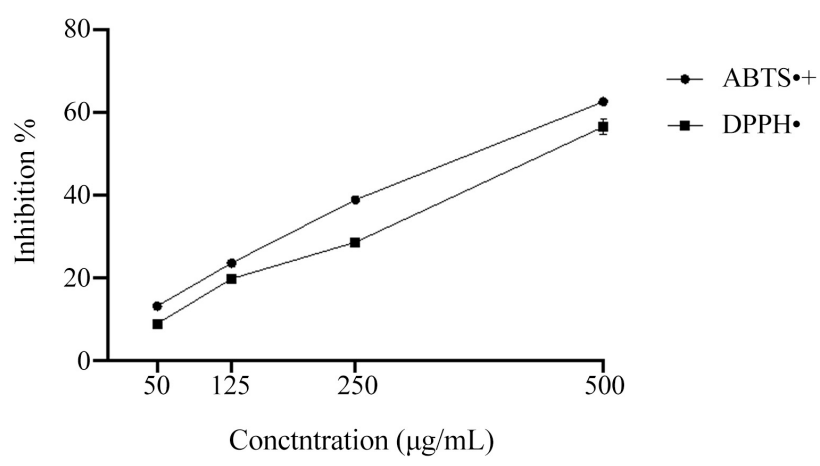

Figure 1. Percent inhibition of $\mathrm{ABTS} \bullet+$ and $\mathrm{DPPH} \bullet$ radicals by red onion extract. Inhibition percentage increased with elevated extract concentrations for both radicals. Results are expressed as mean $\pm S D, n=3$.

ATP extracellular hydrolysis

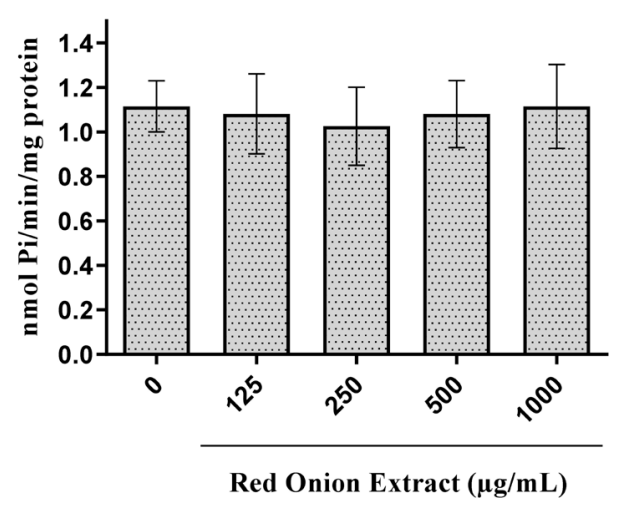

Figure 2. Effect of red onion extract on ATP hydrolysis in rat serum. Results are expressed as mean $\pm S D, n=4$. There were no significant differences between groups. 
ADP extracellular hydrolysis

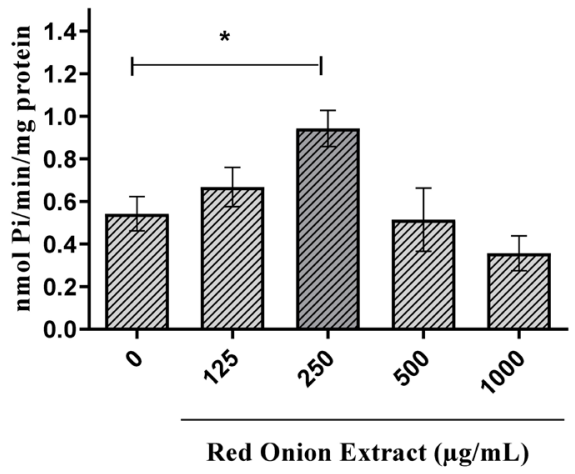

Figure 3. Effect of red onion extract on ADP hydrolysis in rat serum. Results are expressed as mean $\pm \mathrm{SD}, \mathrm{n}=4$. ${ }^{\star}$ Represents a statistically significant difference from the control $(0 \mu \mathrm{g} / \mathrm{mL})$ group $(\mathrm{p}<0.05)$.

AMP extracellular hydrolysis

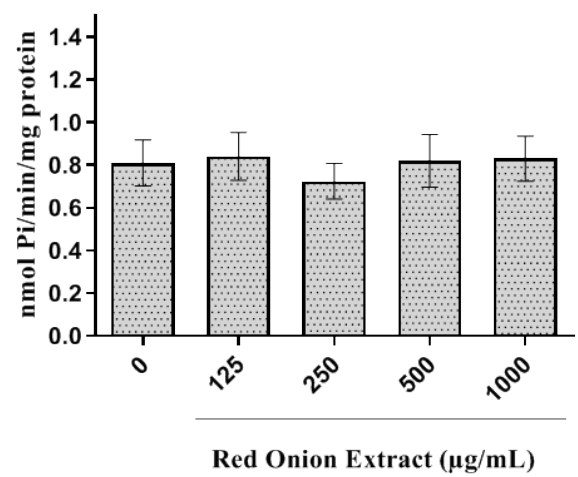

Figure 4. Effect of red onion extract on AMP hydrolysis in rat serum. Results are expressed as mean $\pm \mathrm{SD}, \mathrm{n}=4$. There were no significant differences between groups.

\section{$p$-Nph-5'TMP extracellular hydrolysis}

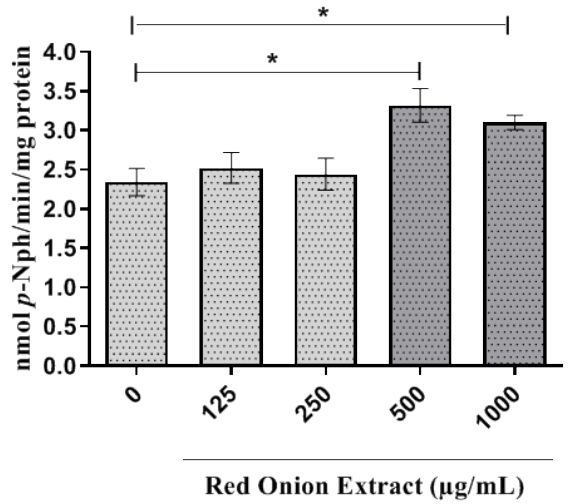

Figure 5. Effect of red onion extract on the artificial substrate marker for E-NPP activity. p-Nph-5'TMP hydrolysis was increased in rat serum treated with 500 and $1000 \mu \mathrm{g} / \mathrm{mL}$ red onion extract. Results are expressed as mean $\pm \mathrm{SD}, \mathrm{n}=3$. ${ }^{\star}$ Represents a statistically significant difference from the control $(0 \mu \mathrm{g} / \mathrm{mL})$ group $(\mathrm{p}<0.05)$. 


\section{Conclusion}

Using the extraction method described in this study, we found high phenolic and flavonoid contents as well as high antioxidant capacity in red onion extract. Considering nucleotide hydrolysis, red onion extract significantly increased the breakdown of ADP and p-Nph-5'-TMP in rat serum. This study presents for the first time the effects of red onion phenolics on serum ectonucleotidase activities. Data evidenced the potential use of this vegetable as an adjuvant in the control and treatment of vascular diseases that compromises purinergic signaling, such as platelet aggregation disturbances and arterial hypertension. Finally, our results point to promising studies on the approach of red onion effects on the components of purinergic signaling, such as in vivo pathophysiological models.

\section{Acknowledgements}

This work was supported by grants from Universidade Federal de Uberlândia (UFU) - Projeto 025 (Edital 04/2014), Conselho Nacional de Pesquisa e Desenvolvimento (CNPq) - Processo: 446747/2014-9 and Fundação de Amparo à Pesquisa do Estado de Minas Gerais (FAPEMIG). JLS was a recipient of a scholarship from FAPEMIG - IC-FAPEMIG20170215.

\section{Conflicts of Interest}

The authors declare no conflicts of interest regarding the publication of this paper.

\section{References}

[1] Burnstock, G. (2016) Short and Long-Term (Trophic) Purinergic Signaling. Philosophical Transactions B, 371, Article ID: 20150422.

https://doi.org/10.1098/rstb.2015.0422

[2] Burnstock, G. (2017) Purinergic Signaling in the Cardiovascular System. Circulation Research, 120, 207-228. https://doi.org/10.1161/CIRCRESAHA.116.309726

[3] Burnstock, G. (2015) Intracellular Expression of Purinoceptors. Purinergic Signaling, 11, 275-276. https://doi.org/10.1007/s11302-015-9455-6

[4] Zimmermann, H. (2001) Ectonucleotidases: Some Recent Developments and a Note on Nomenclature. Drug Development Research, 52, 44-56.

https://doi.org/10.1002/ddr.1097

[5] Yegutkin, G.G. (2008) Nucleotide- and Nucleoside-Converting Ectoenzymes: Important Modulators of Purinergic Signalling Cascade. Biochimica et Biophysica Acta (BBA)-Molecular Cell Research, 1783, 673-694.

https://doi.org/10.1016/j.bbamcr.2008.01.024

[6] Zimmermann, H., Zebisch, M. and Sträter, N. (2012) Cellular Function and Molecular Structure of Ecto-Nucleotidases. Purinergic Signaling, 8, 437-502. https://doi.org/10.1007/s11302-012-9309-4

[7] Bagheri, B., Zargari, M., Meshkini, F., Dinarvand, K., Mokhberi, V., Azizi. S. and Rasouli, M. (2016) Uric Acid and Coronary Artery Disease, Two Sides of a Single Coin: A Determinant of Antioxidant System or a Factor in Metabolic Syndrome. Journal of Clinical and Diagnostic Research, 10, OC27-OC31. 
https://doi.org/10.7860/JCDR/2016/16335.7281

[8] Cipriani, S., Bakshi, R. and Schwarzschild, M.A. (2014) Protection by Inosine in a Cellular Model of Parkinson's Disease. Neuroscience, 274, 242-249.

https://doi.org/10.1016/j.neuroscience.2014.05.038

[9] Martelli, F. and Nunes, F.M.F. (2014) Radicais Livres: Em Busca do Equilíbrio. Ciência e Cultura, 66, 54-57. http://dx.doi.org/10.21800/S0009-67252014000300017

[10] Aalto, T.K. and Raivio, K.O. (1993) Metabolism of Extracellular Adenine Nucleotides by Human Endothelial Cells Exposed to Reactive Oxygen Metabolites. American Journal of Physiology, 264, C282-C286. https://doi.org/10.1152/ajpcell.1993.264.2.C282

[11] Krötz, F., Sohn, H.Y., Keller, M., Gloe, T., Bolz, S.S., Becker, B.F. and Pohl, U. (2002) Depolarization of Endothelial Cells Enhances Platelet Aggregation through Oxidative Inactivation of Endothelial NTPDase. Arteriosclerosis, Thrombosis and Vascular Biology, 22, 2003-2009. https://doi.org/10.1161/01.ATV.0000043454.08172.51

[12] Schmatz, R., Mann, T.R., Spanevello, R., Machado, M.M., Zanini, D., Pimentel, V.C., Stefanello, N., Martins, C.C., Cardoso, A.M., Bagatini, M., Gutierres, J., Leal, C.A.M., Pereira, L.B., Mazzanti, C., Schetinger, M.R. and Morsch, V.M. (2013) Moderate Red Wine and Grape Juice Consumption Modulates the Hydrolysis of the Adenine Nucleotides and Decreases Platelet Aggregation in Streptozotocin-Induced Diabetic Rats. Cell Biochemistry and Biophysics, 65, 129-143. https://doi.org/10.1007/s12013-012-9407-5

[13] Onyeoziri, U.P., Romanus, E.N. and Onyekachukwu, U.I. (2016) Assessment of Antioxidant Capacities and Phenolic Contents of Nigerian Cultivars of Onions (Allium cepa L.) and Garlic (Allium sativum L.). Pakistan Journal of Pharmaceutical Sciences, 29, 1183-1188.

[14] Velioglu, Y.S., Mazza, G., Gao, L. and Oomah, B.D. (1998) Antioxidant Activity and Total Phenolics in Selected Fruits, Vegetables, and Grain Products. Journal of Agricultural and Food Chemistry, 46, 4113-4117. https://doi.org/10.1021/jf9801973

[15] Souza, M.M., Recart, V.M., Rocha, M., Cipolatti, E.P. and Badiale-Furlong, E. (2009) Estudo das Condições de Extração de Compostos Fenólicos de Cebola (Allium cepa L.). Revista do Instituto Adolfo Lutz, 68, 192-200.

[16] Wettasinghe, M. and Shahidi, F. (1999) Evening Primrose Meal: A Source of Natural Antioxidants and Scavenger of Hydrogen Peroxide and Oxygen-Derived Free Radicals. Journal of Agriculture and Food Chemistry, 47, 1801-1812. https://doi.org/10.1021/jf9810416

[17] Hossain, M.A. and Rahman, S.M.M. (2011) Total Phenolics, Flavonoids and Antioxidant Activity of Tropical Fruit Pineapple. Food Research International, 44, 672-676. https://doi.org/10.1016/j.foodres.2010.11.036

[18] Re, R., Pellegrini, N., Proteggente, A., Pannala, A., Yang, M. and Rice-Evans, C. (1999) Antioxidant Activity Applying an Improved ABTS Radical Cation Decolorization Assay. Free Radical Biology and Medicine, 26, 1231-1237.

https://doi.org/10.1016/S0891-5849(98)00315-3

[19] Brand-Williams, W., Cuvelier, M.E. and Berset, C. (1995) Use of a Free radical Method to Evaluate Antioxidant Activity. LWT, 28, 25-30.

https://doi.org/10.1016/S0023-6438(95)80008-5

[20] Oses, J.P., Cardoso, C.M., Germano, R.A., Kirst, I.B., Rücker, B., Fürstenau, C.R., Wink, M.R., Bonan, C.D., Battastini, A.M.O. and Sarkis, J.J. (2004) Soluble 
NTPDase: An Additional System of Nucleotide Hydrolysis in Rat Blood Serum. Life Sciences, 74, 3275-3284. https://doi.org/10.1016/j.lfs.2003.11.020

[21] Chan, K.M., Delfert, D. and Junger K.D. (1986) A Direct Colorimetric Assay for Ca2+ Stimulated ATPase Activity. Analytical Biochemistry, 157, 375-380. https://doi.org/10.1016/0003-2697(86)90640-8

[22] Sakura, H., Nagashima, S. and Nakashima, A. (1998) Characterization of Fetal Serum 5'-Nucleotide Phosphodiesterase: A Novel Function as a Platelet Aggregation Inhibitor in Fetal Circulation. Thrombosis Research, 91, 83-89. https://doi.org/10.1016/S0049-3848(98)00073-5

[23] Galdón, B.R., Rodriguéz, E.M.R. and Romero, C.D. (2008) Flavonoids in Onion Cultivars (Allium cepa L.). Journal of Food Science, 73, C599-C605. https://doi.org/10.1111/j.1750-3841.2008.00903.x

[24] Santas, J., Carbó, R. and Gordon, M.H. (2008) Comparison of the Antioxidant Activity of Two Spanish Onion Varieties. Food Chemistry, 107, 1210-1216. https://doi.org/10.1016/j.foodchem.2007.09.056

[25] Nuutila, A.M., Puupponen-Pimiä, R., Aarni, M. and Oksman-Caldentey, K.M. (2003) Comparison of Antioxidant Activities of Onion and Garlic Extracts by Inhibition of Lipid Peroxidation and Radical Scavenging Activity. Food Chemistry, 81, 485-493. https://doi.org/10.1016/S0308-8146(02)00476-4

[26] Srinivasan, K. (2014) Antioxidant Potential of Spices and Their Active Constituents. Critical Reviews in Food Science and Nutrition, 54, 352-372.

https://doi.org/10.1080/10408398.2011.585525

[27] Prakash, D., Singh, B.N. and Upadhyay, G. (2007) Antioxidant and Free Radical Scavenging Activities of Phenols from Onion (Allium cepa). Food Chemistry, 102, 1389-1393. https://doi.org/10.1016/j.foodchem.2006.06.063

[28] Floegela, A., Kim, D.O., Chung, S.J., Sung, I.K. and Chun, O.K. (2011) Comparison of ABTS/DPPH Assays to Measure Antioxidant Capacity in Popular Antioxidant-Rich US Foods. Journal of Food Composition and Analysis, 24, 1043-1048. https://doi.org/10.1016/j.jfca.2011.01.008

[29] Dudonné, S., Vitrac, X., Coutière, P., Woillez, M. and Mérillon, J-M. (2009) Comparative Study of Antioxidant Properties and Total Phenolic Content of 30 Plant Extracts of Industrial Interest Using DPPH, ABTS, FRAP, SOD, and ORAC Assays. Journal of Agricultural and Food Chemistry, 57, 1768-1774. https://doi.org/10.1021/jf803011r

[30] Aoki, J. (2004) Mechanisms of Lysophosphatidic Acid Production. Seminars in Cell and Developmental Biology, 15, 477-489. https://doi.org/10.1016/j.semcdb.2004.05.001

[31] Fürstenau, C.R. (2010) Participation of Purinergic Signaling in L-NAME Induced Arterial Hypertension. Ph.D. Dissertation, Universidade Federal do Rio Grande do Sul, Brazil, 1-157.

[32] Maffrand, J.P., Bernat, A., Delebassee, D., Defreyn, G., Cazenave, J. and Gordon, J.L. (1988) ADP Plays a Key Role in Thrombogenesis in Rats. Thrombosis and Haemostasis, 59, 225-230. https://doi.org/10.1055/s-0038-1642759

[33] Zimmermann, H. (1992) 5'-Nucleotidase: Molecular Structure and Functional Aspects. Biochemical Journal, 285, 345-365. https://doi.org/10.1042/bj2850345

[34] Stefan, C., Jansen, S. and Bollen, M. (2006) Modulation of Purinergic Signaling by NNP-Type Ectophosphodiesterases. Purinergic Signaling, 2, Article No. 361. https://doi.org/10.1007/s11302-005-5303-4 
[35] Johnson, K., Polewski, M., Etten, D.V. and Terkeltaub, R. (2005) Chondrogenesis Mediated by PPi Depletion Promotes Spontaneous Aortic Calcification in NPP1-/-Mice. Arteriosclerosis, Thrombosis and Vascular Biology, 25, 686-691.

https://doi.org/10.1161/01.ATV.0000154774.71187.f0

[36] Villa-Bellosta, R., Wang, X.N. and Millán, J.L. (2011) Extracellular Pyrophosphate Metabolism and Calcification in Vascular Smooth Muscle. American Journal of Physiology-Heart Circulation Physiology, 301, H61-H68.

https://doi.org/10.1152/ajpheart.01020.2010 